\title{
Behaviour of Thermal Power Plant Boiler Support Steel Structure under Seismic Excitations
}

\author{
R. Arun Kumar ${ }^{1}$ and C. Umarani ${ }^{2}$ \\ ${ }^{1}$ M. S. Scholar, ${ }^{2}$ Professor, ${ }^{1 \& 2}$ Department of Civil Engineering, \\ Division of Structural Engineering, College of Engineering Guindy, Anna University, Tamil Nadu, India \\ E-Mail: aruninkumar@gmail.com,umarani@annauniv.edu
}

\begin{abstract}
Static and dynamic analysis of a thermal power plant boiler support steel structure is carried out to study its behaviour and responses. Non-Linear Time History Analysis (NLTHA) method is adopted to study the behaviour and response of the structure in addition with Equivalent Static Analysis (ESA) and Response Spectrum Analysis (RSA) methods using SAP2000 software application. Though NLTHA method is not used extensively in Indian boiler support structure design practices, in the present study, an attempt is made to study about the realistic behaviour and performance of boiler support steel structure using NLTHA. Three different ground motions are used for analysing the boiler support steel structure with compatible scale factors and during the analysis, behaviour of the structure under different seismic excitations are usually compared in terms of [5] loaddeflection, moment-rotation, moment-curvature and stressstain relationships. Hence it is found that NLTHA method provides more accurate and dynamic results compared to the ESA and RSA methods. Various seismic demand parameters like mode shapes, displacements, drifts, base shear forces, floor accelerations and floor response spectra curves are presented in the results to understand the behaviour and response of the boiler support steel structures during the seismic excitations. Keywords: Boiler Support Steel Structure, Ground Motion, Equivalent Static, Response Spectrum, Non-Linear Time History, SAP2000, Scale Factor, Mode Shape and Excitations
\end{abstract}

\section{INTRODUCTION}

There exists a wide range of boiler support steel structures in thermal power plants and the type of structural system used depend on its functional and the capacity requirements. In the present study, the supercritical thermal power plant boiler support steel structure is designed for the weights corresponding to $660 \mathrm{MW}$ boiler capacity. The boiler support steel structure is usually intended to take around 50000 tonnes of various vertical loads along with lateral loads. The height of the structure is $85 \mathrm{~m}$ and the dead weight is around 10000 tonnes. Therefore, the lateral loads due to the seismic effects are also considerably on the higher side, and hence it is essential to study the behaviour and response of the boiler support steel structure under the seismic excitations for the economic design [6].

It is impossible to exactly determine the earthquake induced forces that are expected to cause high damage or failure in the structure. Dynamic analysis of the boiler structure is more complex than the other structures due to the irregularities in the mass and the geometry hence this study focuses mainly on understanding the behaviour and response of boiler support steel structures by comparing the results of various analysis methods which are adopted.

\section{LITERATE REVIEW}

Cruz, et al., [13], studied the seismic behaviour of a heavy industrial boiler built in Chile using push over analysis and Time history analysis. During seismic incidents the inelastic deformations occurred first in the seismic guides (stoppers) and then in the vertical bracings, and the large lateral displacements caused column damages. The results revealed that design of the typical boiler support structure, carried out by response spectrum analysis can be considered validated by the pushover analysis results.

Hari Krishna, et al., [14], explored the uses of Concrete Filled Square Steel Tubular (CFST) columns in boiler support structures which reduces the natural period by $21 \%$, drift by $40 \%$ and the base shear increases by nearly $33 \%$ over the steel plus-I columns with pinned base assumption. The study results show that the use of CFST columns in boiler structures provides considerable cost saving in addition to its better structural performance.

As per Motoki Kato, et al., [15], Seismic response control device (hysteresis damper) and M-FRAME (Mitsubishi Frame weight Reduction Algorithm for Multiple Elements) steel frame cross section minimizing rational techniques are applied to the main member design of plant support steel frames for the better performance. The boiler support steel weight reduction of about $10 \%$ was obtained due to the application of the steel frame weight minimizing method.

Kiyoshi Muto, et al., [16], studied the response of a 1000 MW boiler and its support structure and found that the behaviour of the structure is largely affected by not only the rigidity and strength of steel members but also by stiffness and strength of the seismic ties. The developed analytical method, is capable of considering nonlinearities due to not only buckling of the brace but also to the interaction between the boiler and adjacent frames and also, it was proved that this new analytical approach is a practical design method for the boiler buildings. 


\section{STRUCTURAL MODELING AND SEISMIC ANALYSIS}

In this study an Indian based super critical thermal power plant boiler support steel structure is modelled and analysed in three-dimensional environment using SAP2000 [4] software application. The space frame option in this Finite Element Analysis (FEA) based application envisages the geometric nonlinearity and material nonlinearity during static and dynamic excitations.

\section{A. Model Geometry and Code Standards}

Boiler support steel structure geometry details, boundary conditions and the code standards are listed in the Table I. The Fig. 1 shows the basic isometric view of the boiler Support steel Structure SAP model.

TABLE I STRUCTURE GEOMETRY AND DESIGN DATA

\begin{tabular}{|c|c|}
\hline \multicolumn{2}{|c|}{ Basic Details } \\
\hline Height of the Structure & $85 \mathrm{~m}$ \\
\hline Plan Dimension & $88 \mathrm{~m} \times 90 \mathrm{~m}$ \\
\hline $\begin{array}{l}\text { Frame Sections used } \\
\text { Column, Beams \& } \\
\text { Vertical Braces }\end{array}$ & $\begin{array}{c}\text { Plate fabricated } \\
\text { sections \& Hot rolled } \\
\text { section }\end{array}$ \\
\hline $\begin{array}{l}\text { Sections used for } \\
\text { Horizontal Braces }\end{array}$ & $\begin{array}{c}\text { Angles \& Circular } \\
\text { Hollow Sections }\end{array}$ \\
\hline Boiler Layout Type & Front Mill Type \\
\hline \multicolumn{2}{|c|}{ Boundary Conditions } \\
\hline Column Base & Fixed \\
\hline Beam - Column & Moment connection \\
\hline Girder - Beam & Pinned connection \\
\hline $\begin{array}{l}\text { Vertical \& Horizontal } \\
\text { Bracings }\end{array}$ & Pinned connection \\
\hline Post and Hanger & $\begin{array}{l}\text { Moment \& Pinned } \\
\text { connection }\end{array}$ \\
\hline \multicolumn{2}{|c|}{ Material Properties } \\
\hline Elastic Modulus (E) & $2.0 \times 105 \mathrm{~N} / \mathrm{mm}^{2}$ \\
\hline Poisson's Ratio (u) & 0.3 \\
\hline Density of Steel & $78.5 \mathrm{kN} / \mathrm{m}^{3}$ \\
\hline $\begin{array}{l}\text { Coefficient of Thermal } \\
\text { Expansion }\end{array}$ & $1.2 \times 10^{-5} /{ }^{0} \mathrm{C}$ \\
\hline Damping & $2 \%$ \\
\hline \multicolumn{2}{|c|}{ Code Standards } \\
\hline Dead Load & IS: 875-Part-1-1987 \\
\hline Imposed Load & IS: 875-Part-2-1987 \\
\hline Wind Load & IS: 875-Part-3-1987 \\
\hline $\begin{array}{l}\text { Code of Practice for Steel } \\
\text { Construction }\end{array}$ & IS: 800-1984 \\
\hline $\begin{array}{l}\text { Earth Quake Resistant } \\
\text { Design of Structures }\end{array}$ & $\begin{array}{l}\text { IS: } 1893-P a r t-1 \& 4- \\
2002 / 2005\end{array}$ \\
\hline Concrete Code & IS: $456-2000$ \\
\hline
\end{tabular}

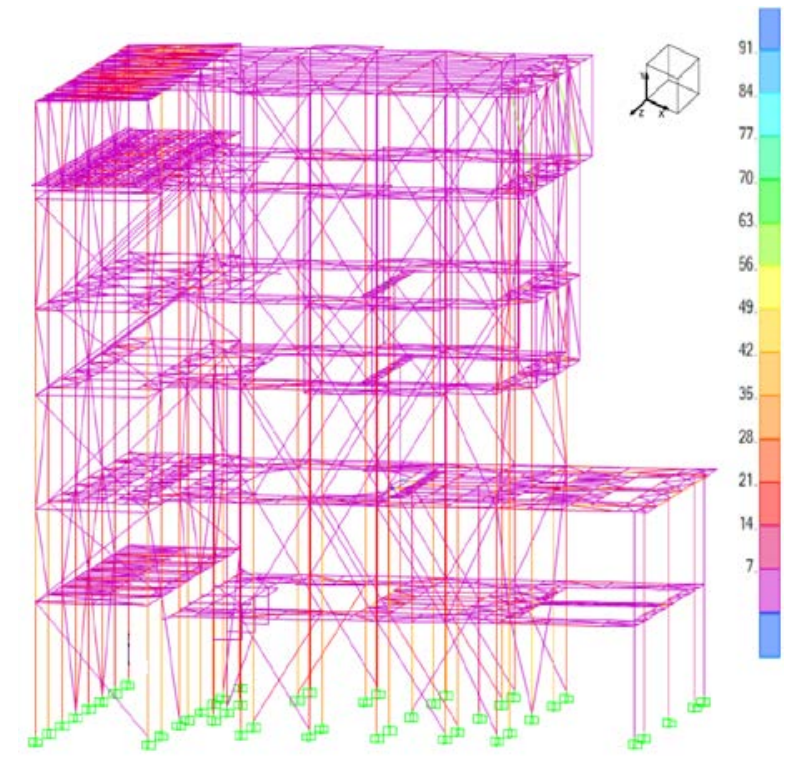

Fig. 1 SAP model - Isometric view

\section{B. Loads and Combinations}

The following fundamental loads are calculated as per the given details and sequentially applied in the SAP model for the analysis.

\section{Dead Load - DL}

Steel materials unit weight $=76.98 \mathrm{kN} / \mathrm{m}^{3}$

Grating floors $\quad=0.60 \mathrm{kN} / \mathrm{m}^{2}$

Concrete floor $\quad=6.00 \mathrm{kN} / \mathrm{m}^{2}$

\section{Imposed Load - IL}

$\begin{array}{ll}\text { Grating floors } & =5.00 \mathrm{kN} / \mathrm{m}^{2} \\ \text { Stairs and landings } & =5.00 \mathrm{kN} / \mathrm{m}^{2} \\ \text { Feeder \& Tripper floor } & =15.00 \mathrm{kN} / \mathrm{m}^{2} \\ \text { Roof } & =0.75 \mathrm{kN} / \mathrm{m}^{2}\end{array}$

As per clause 9.1 of IS: 1893 (part-4) 25\% of live load considered for seismic weight calculation of various floors.

\section{Wind Load - WL}

Wind load on Boiler support structure was calculated as per IS: 875 Part-3[3] and applied on the members as uniformly distributed loads (UDL).

Design wind Pressure $=\mathrm{P}_{\mathrm{z}}=0.6 \mathrm{Vz}^{2}$

Basic wind speed $=\mathrm{V}_{\mathrm{b}} \quad=47 \mathrm{~m} / \mathrm{sec}$

Terrain category $\quad=2$ (class-c)

Probability factor $\left(\mathrm{k}_{1}\right) \quad=1.07$

Terrain Factor $\left(\mathrm{k}_{2}\right) \quad=0.93$ to 1.1

Topography factor $\left(\mathrm{k}_{3}\right) \quad=1.0$

Wind force $\mathrm{F} \quad=\left(\mathrm{C}_{\mathrm{pe}}-\mathrm{C}_{\mathrm{pi}}\right) * \mathrm{~A} * \mathrm{P}_{\mathrm{z}}$ $\mathrm{C}_{\mathrm{pi}}= \pm 0.2 \& \mathrm{C}_{\mathrm{pe}}=$ varies from 0.8 to 0.5 


\section{Seismic Load - SL}

The schematic methodology of calculating static and dynamic loads are as per IS 1893[1].

$\begin{array}{ll}\text { Seismic Zone } & =\mathrm{II} \\ \text { Soil condition } & =\text { Medium } \\ \text { Zone factor (Z) } & =0.1 \\ \text { Importance factor (I) } & =1.75 \\ \text { Response reduction factor } & =4.0 \\ \text { Damping } & =0.02 \\ \text { Spectral acceleration } & =1.39 / \mathrm{T} \\ \text { Time Period } & =0.075 * \mathrm{~h}^{0.75} \\ & =2.09 \mathrm{Sec}\end{array}$

\section{Load Combinations}

a. $D L \pm I L$

b. $D L \pm I L \pm Q^{*} \pm S L / W L$

c. $D L \pm I L \pm Q^{*} \pm T^{*}$

d. $0.75 D L \pm S L / W L$

*Equipment Loads in operating (Q) \& Temperature Loads (T) details are directly applied in the SAP models as per standard practices [3].

\section{Seismic Analysis}

There are five similar SAP models are prepared for three different analysis methods. In that two models are prepared as per the ESA and RSA requirements. Similarly, another three models are prepared for NLTHA requirements with three different time history functions to validate the results.

Brief description and details about three different method of seismic analysis are as follows.

$$
\begin{aligned}
& \text { No. of Joints }=2474 \\
& \text { Restraints }=47 \\
& \text { No. of Frames }=5072 \\
& \text { Degrees of Freedom }=14562 \text { (stiffness) } \\
& \text { Degrees of Freedom }=7281 \text { (mass) }
\end{aligned}
$$

Before starting the seismic analysis, the basic selection of the members are done as per IS: 800 [2] because the seismic excitations are also one of the function of member stiffness.

\section{Equivalent Static Analysis}

In equivalent static analysis, the total base shear is calculated as a product of horizontal seismic coefficient, and total weight of the structure [10]. The value of horizontal seismic coefficient depends on the seismic zone, type of construction foundation conditions and the importance of the structure. The load generally has an inverted parabolic distribution along the height of the structure. A static analysis with these lateral loads yields the induced element forces.
Design base shear $\mathrm{V}_{\mathrm{b}}=\mathrm{A}_{\mathrm{h}} \mathrm{W}$ [7]

$\mathrm{A}_{\mathrm{h}}=$ Design horizontal acceleration spectrum value

$\mathrm{A}_{\mathrm{h}}=(\mathrm{Z} / 2) *(\mathrm{I} / \mathrm{R}) *\left(\mathrm{~S}_{\mathrm{a}} / \mathrm{g}\right)$

$\mathrm{W}=$ Seismic weight of building

$=$ Dead load + appropriate amount of imposed load.

\section{Response Spectrum Analysis}

Response spectrum method uses the seismic excitation represented in terms of a response spectrum as the exciting force [10]. The free vibration analysis of the structure determines the natural frequencies of each mode. Peak response of the structure at each mode is determined from the response spectrum by knowing the natural frequency/time period corresponding to that mode. The responses are then obtained using complete quadratic combination (CQC) rule and it can account for modal coupling methods suggested by IS: 1893[1].

a. Mass $\mathrm{m}$ times acceleration a, representing inertia force, or Stiffness K times displacement $\mathrm{x}$ representing elastic force, i.e., $\mathrm{F}=\mathrm{ma}$ or $\mathrm{F}=\mathrm{Kx}$. Medium soil spectral acceleration as per Fig no. 2 with specified mass sources are used in this RSA to excite the boiler support structure.

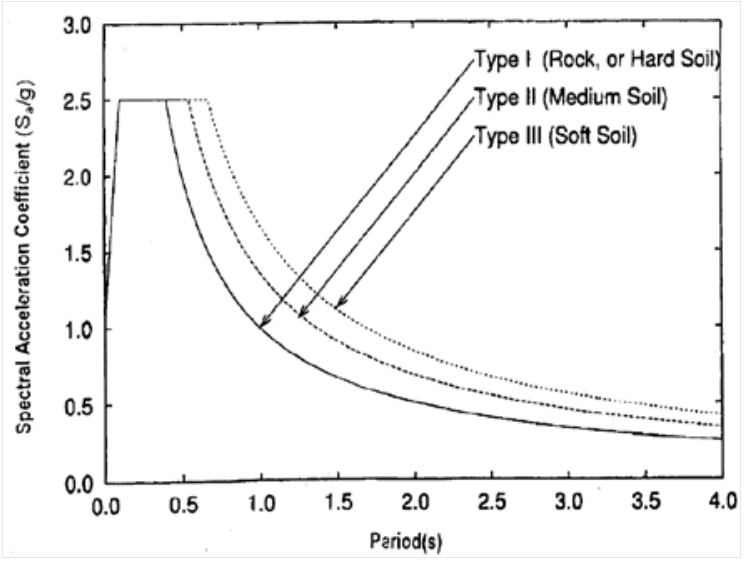

Fig. 2 IS-1893 part-1 (2002) Response spectra [1]

\section{Non-Linear Time History Analysis}

In time history analysis method, the input motion is a prescribed function of time such as acceleration versus time, or displacement versus time [10]. The analysis consists of a time integration of the equations of motion. Either the coupled equations of motion or the uncoupled equations of motion as is the case of modal analysis can be treated in this method.

The modal time history uses method of mode supervision, compared with direct integration which solves the equation for each time step. In modal superposition method dynamic response of the structure can be approximated by superposition of a small number of its Eigen modes [12]. The basic idea is to use free vibrations mode shapes to 
uncouple equations of motion. The uncoupled equations are in terms of new variables called the modal coordinate. Solution for modal coordinates can be obtained by solving each equation independently. A superposition of modal coordinates then gives solution of the original equation.

Three ground motions with different PGA levels are selected from the Strong-motion Virtual Data Centre [17] for this NLTHA. Below mentioned (Table II) ground motion are scaled and used for these seismic excitations in the structure. The zone factors [9] and the approximate PGAs are also presented in the Table III.

TABLE II TIME HistoRy DATA

\begin{tabular}{|c|c|c|c|c|}
\hline S. No. & $\begin{array}{c}\text { Time } \\
\text { History }\end{array}$ & $\begin{array}{c}\text { PGA } \\
\text { (g) }\end{array}$ & Magnitude & Component \\
\hline 1 & TH-1 & $0.106 \mathrm{~g}$ & 7 & $\begin{array}{c}\text { Lat 23 02 N } \\
\text { Long 72.38 E }\end{array}$ \\
\hline 2 & TH-2 & $0.013 g$ & 6 & $\begin{array}{c}\text { Lat 11.66 N } \\
\text { Long 92.74 E }\end{array}$ \\
\hline 3 & TH-3 & $0.023 g$ & 7.4 & $\begin{array}{c}\text { Lat 11.66 N } \\
\text { Long 92.74 E }\end{array}$ \\
\hline
\end{tabular}

a. TH-1 Bhuj earthquake (26/01/2001 at 08:46:42)

b. TH-2 Andaman earthquake (10/08/2008 at 08:20:34)

c. TH-3 South western - Pakistan earthquake (18/01/2011 at 20:23:27)

TABle III PeAK GRound AcCelerations (PGA) DATA

\begin{tabular}{|c|c|c|}
\hline $\begin{array}{c}\text { Seismic } \\
\text { Zone }\end{array}$ & PGA (g) & $\begin{array}{c}\text { Zone } \\
\text { Factor (Z) }\end{array}$ \\
\hline 5 & $>0.30 \mathrm{~g}$ & 0.36 \\
\hline 4 & $0.20-0.30 \mathrm{~g}$ & 0.24 \\
\hline 3 & $0.10-0.20 \mathrm{~g}$ & 0.16 \\
\hline 2 & $<0.10 \mathrm{~g}$ & 0.1 \\
\hline
\end{tabular}

\section{RESULTS AND DISCUSSION}

The series of various analysis results are presented in the form of comparison of mode shapes, lateral displacements, drift, base shear, floor accelerations and [8] response spectra curves of boiler support steel structures.

\section{A. Mode Shapes}

From the NLTHA \& RSA, the first two mode shapes of this structure are in $\mathrm{Z}$ and $\mathrm{X}$ direction translational and the third mode shape is in Torsional behaviour. These mode shapes bear a resemblance to the usual behaviour [11] of the structure in dynamic condition which is shown in the Fig. 3 and the corresponding Time periods are presented in the Table IV.

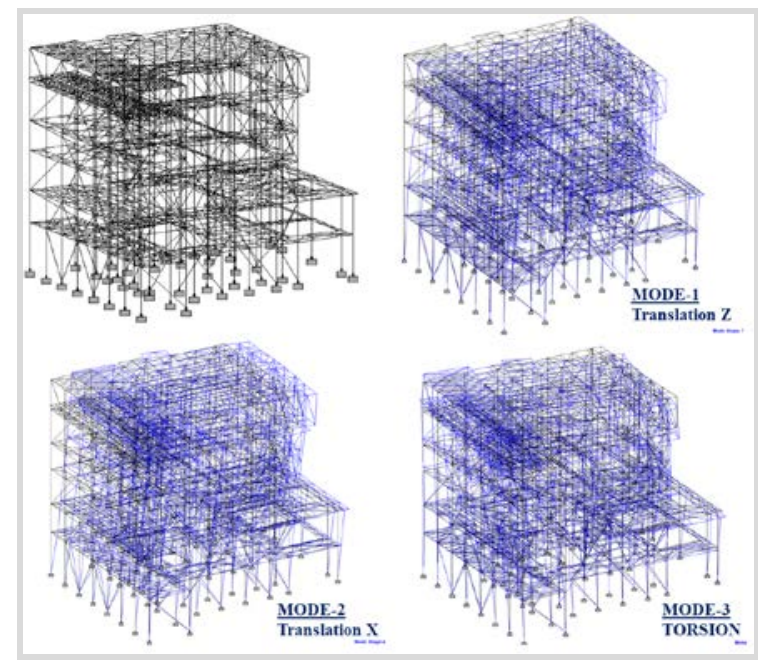

Fig. 3 Mode shapes

TABLE IV TIME PERIOD DETAILS

\begin{tabular}{|c|c|c|}
\hline Mode & $\begin{array}{c}\text { Frequency } \\
\text { Cycle/sec (Hz) }\end{array}$ & $\begin{array}{c}\text { Time Period } \\
\text { (Seconds) }\end{array}$ \\
\hline 1 & 0.306 & 3.258 \\
\hline 2 & 0.360 & 2.776 \\
\hline 3 & 0.491 & 2.032 \\
\hline
\end{tabular}

\section{B. Lateral Displacements}

All the lateral (nodal) displacements from the analysis results are shown in Fig. no 4. The drift analysis presented in the Table III is asper the IS $1893^{[1]}$ clause no.7.11.1. Drift in any storey due to the minimum design lateral force, with partial load factor of 1.0 shall not exceed 0.004 times the storey height.

The maximum lateral displacements are due to the Bhuj TH. Graphical details and curvature of the critical node are shown in the Fig. 5 and 6.

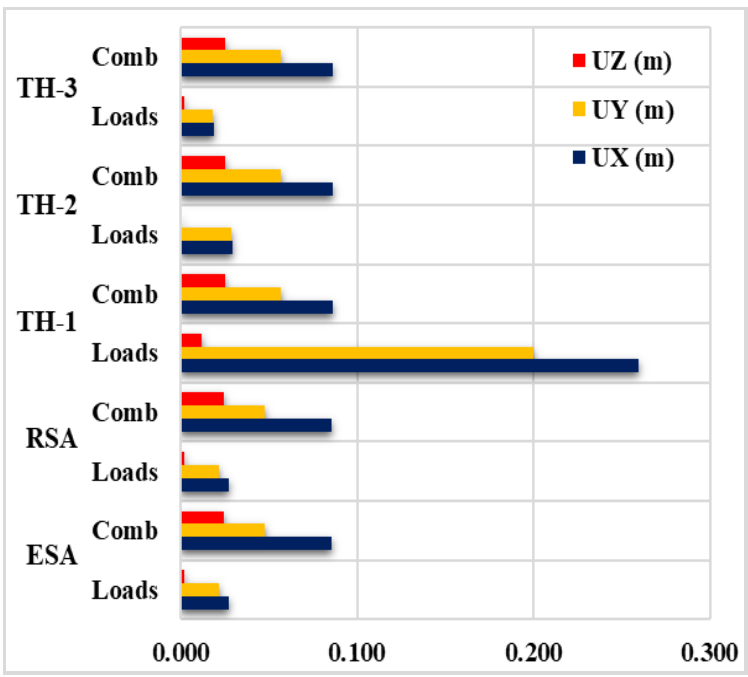

Fig. 4 Maximum lateral displacements 


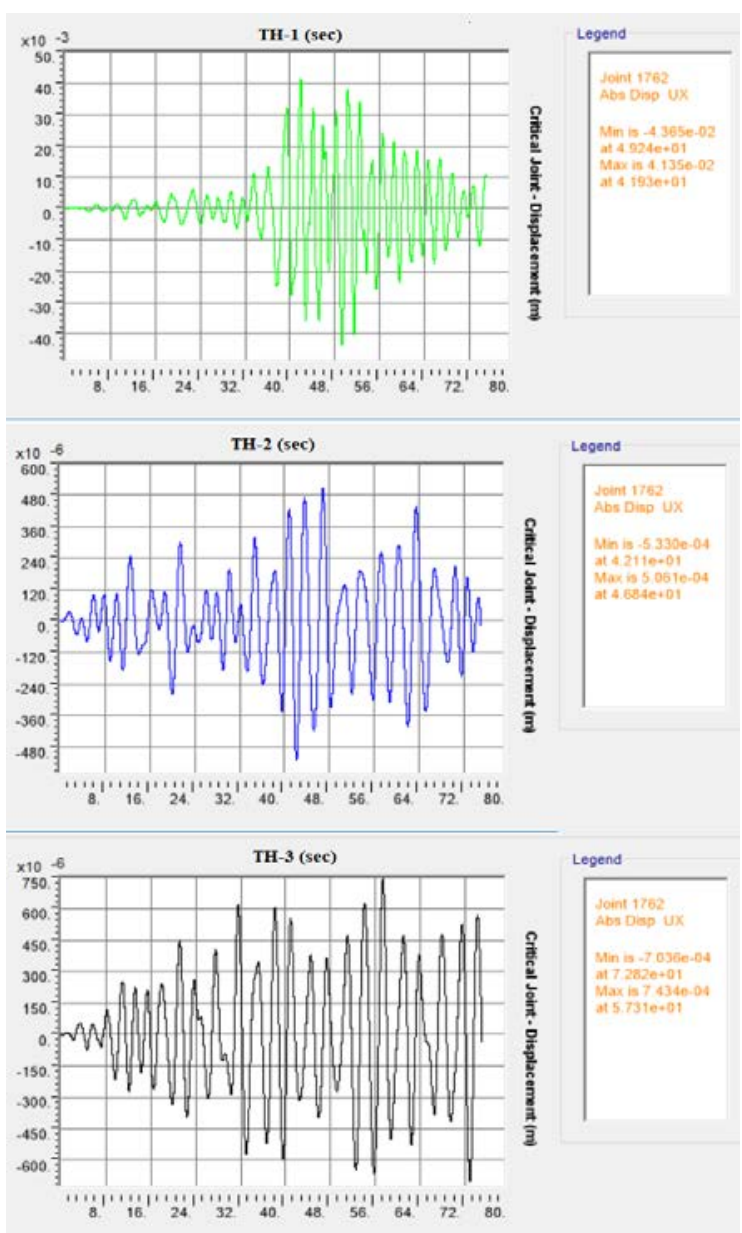

Fig. 5 Peak roof displacements (UY-Dir)
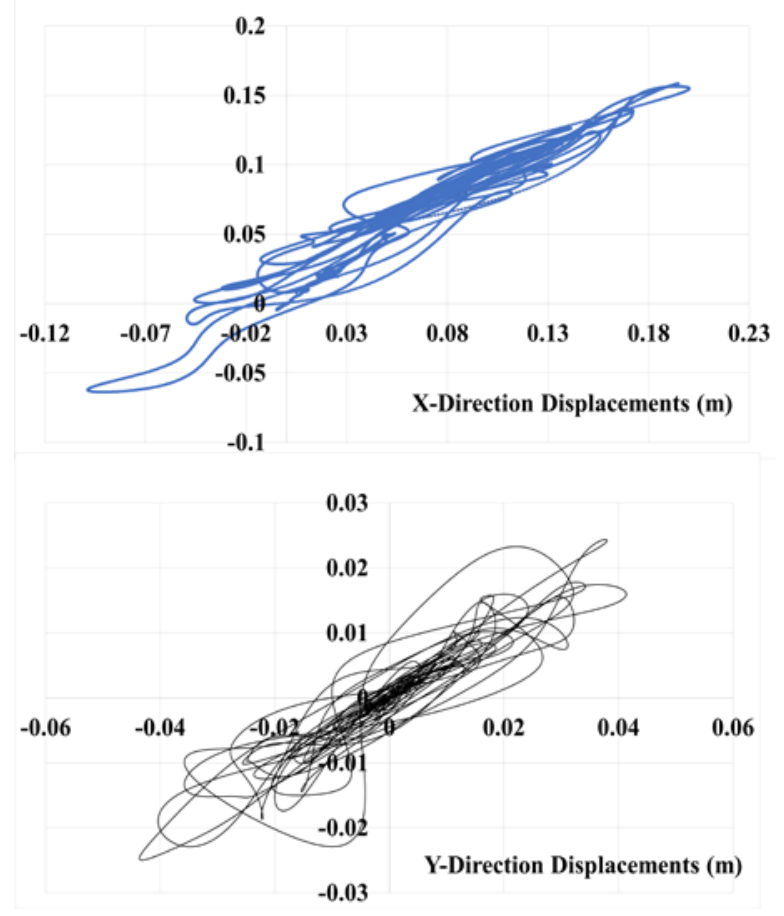

Fig. 6 Critical node displacement of Bhuj TH
C. Drift Analysis

TABLE IV COMPARISON OF MAX DRIFT

\begin{tabular}{|c|c|c|c|c|}
\hline \multicolumn{5}{|c|}{ ESA } \\
\hline Drift & UX (m) & UY (m) & UZ (m) & $\mathbf{0 . 0 0 4 * H}$ \\
\hline Max & 0.086 & 0.048 & 0.025 & 0.332 \\
\hline \multicolumn{5}{|c|}{ RSA } \\
\hline Max & 0.086 & 0.048 & 0.025 & 0.332 \\
\hline \multicolumn{5}{|c|}{ NLTHA-1 } \\
\hline Max & 0.088 & 0.091 & 0.096 & 0.332 \\
\hline \multicolumn{5}{|c|}{ NLTHA-2 } \\
\hline Max & 0.030 & 0.029 & 0.029 & 0.332 \\
\hline \multicolumn{5}{|c|}{ NLTHA-3 } \\
\hline Max & 0.021 & 0.018 & 0.023 & 0.332 \\
\hline
\end{tabular}

\section{Base Shear}

Bhuj TH resulting with higher base shear in the NLTHA than the others since the Bhuj has the high PGA (peak acceleration $=1.0382 \mathrm{~m} / \mathrm{sec}^{2}$ ) and the comparisons are shown in the Fig. 7 with different seismic zones.

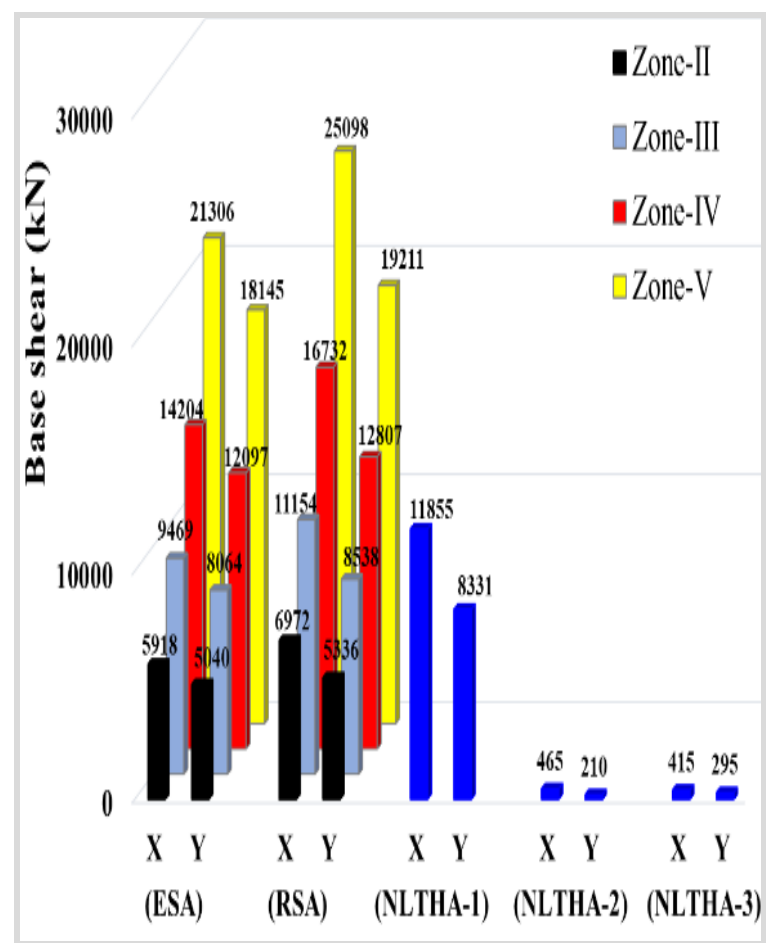

Fig. 7 Base Shear details

\section{E. Floor Accelerations}

The elevation wise floor accelerations of the Bhuj TH is shown in the Fig. 8 [8]. The response spectra curve for roof node and various spectra comparisons for the structural performance are presented in the Fig. 9 \& 10 . 


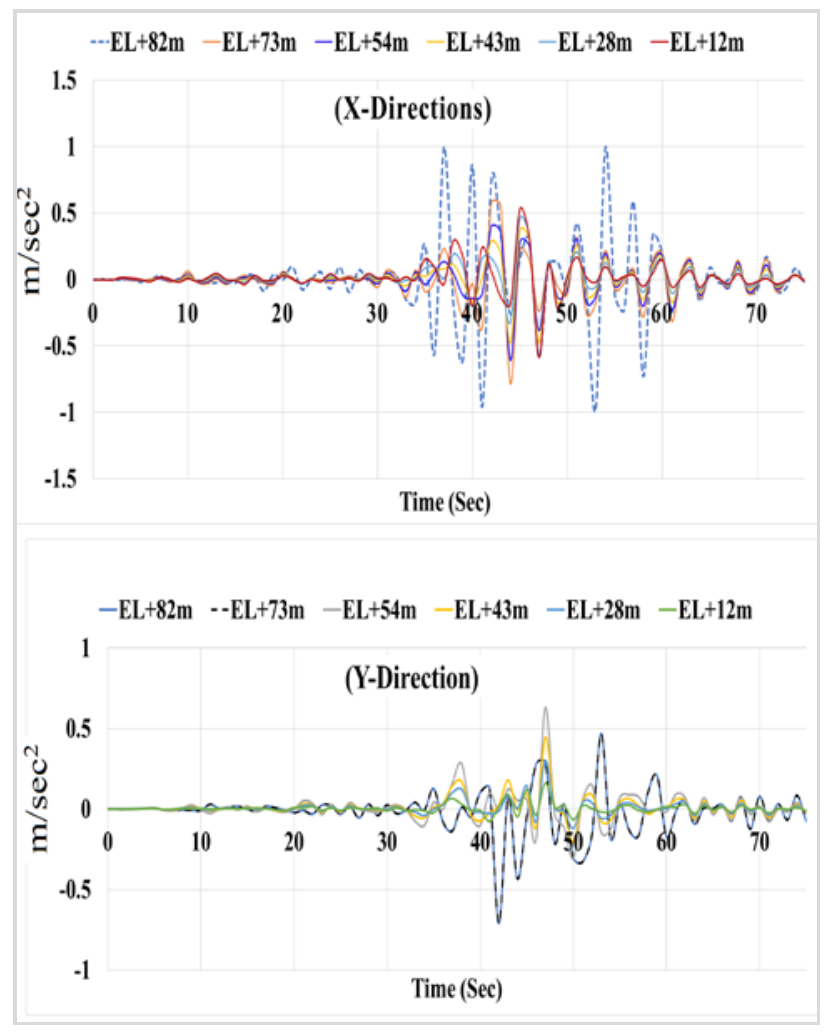

Fig. 8 Peak floor accelerations

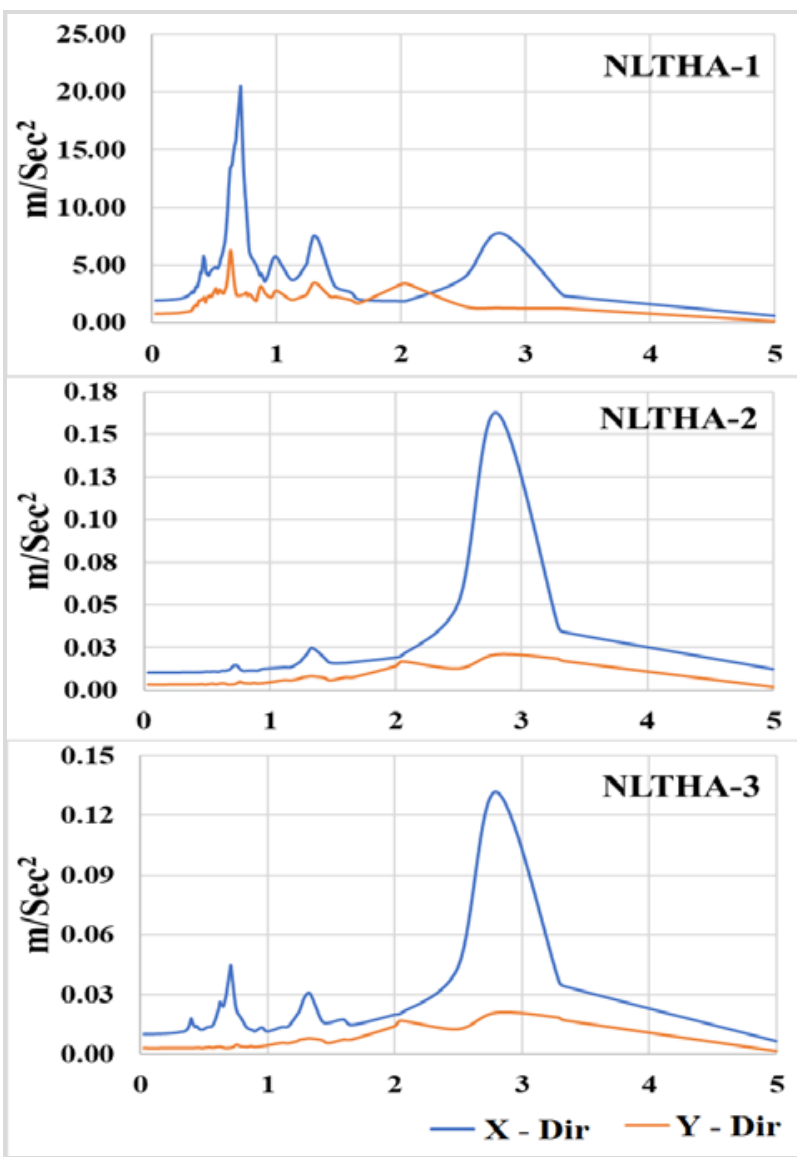

Fig. 9 Roof Acceleration response spectra

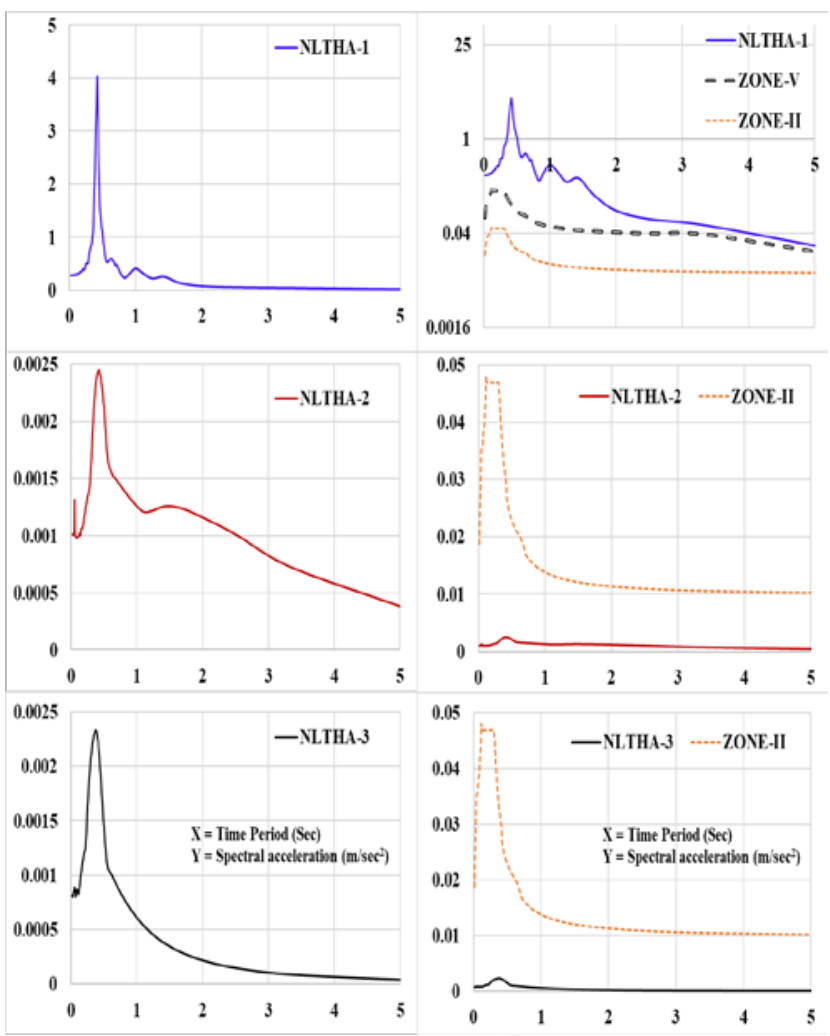

Fig. 10 Response spectra comparisons

\section{CONCLUSION}

In this paper, the behaviour and response of the thermal power plant boiler support steel structure is studied by adopting ESA, RSA \& NLTHA methods. The major conclusions drawn from the study are as follows.

1. The response of the structure in terms of displacements, drift and other accelerations are compared and found that NLTHA method shows the better and accurate results with the three selected time histories for the boiler support steel structure.

2. Bhuj TH in NLTHA gives higher base shear than the other selected THs and the RSA method results are coinciding with PGA levels.

3. First few mode shapes of the boiler support steel structures are in the order of usual behavior and the selected boiler support steel structure performance in the past earthquakes are well within the codal response spectrum except for the Bhuj earthquake.

4. Hence the important structures like thermal power plant boiler support steel structures should be analyzed with NLTHA for the better predictions of the seismic forces and behaviour to achieve the more reliable design conclusions.

\section{NOMENCLATURE}

TH Time History (seconds)

ESA Equivalent Static Analysis

RSA Response Spectrum Analysis 


\author{
NLTHA Non-linear Time History Analysis \\ TH Time History \\ PGA Peak Ground Acceleration \\ Sa Spectral accelerations $\left(\mathrm{m} / \mathrm{sec}^{2}\right)$ \\ DIR Direction \\ MW Mega Watt \\ UX Forces on X-Direction \\ UY Forces on Y-Direction \\ UZ Forces on Z-Direction (vertical) \\ COMB Load Combinations \\ Fig. Figure \\ No. Number \\ $\mathrm{C}_{\mathrm{pe}} \& \mathrm{C}_{\mathrm{pi}}$ External and Internal pressure coefficients
}

\section{ACKNOWLEDGMENT}

The authors are extremely indebted and thankful to Mr. K. Chinna Rao, Vice President and Head of Engineering and Mr. B.K. Chaurasia, Joint General Manager and Head of civil-structural department of L\&T MHPS Boilers Pvt. Ltd., Faridabad-NCR, India for the extended support.

\section{REFERENCES}

[1] IS 1893 (Par-1 \& 4) Criteria for Earthquake Resistant Design of Structures.

[2] IS: 800-1984 \& 2007 Indian Standard code of practice for general construction of steel.

[3] IS: 875 (Part 1 to 3) - 1987 Code of practices for loads.

[4] Computers \& Structures Inc, SAP2000, Automated Lateral Loads, October 2016.
[5] C. V. R. Murty, Rupen Goswami, A. R. Vijayanarayanan and Vipul V. Mehta, "Some Concepts in Earthquake Behaviour of Buildings".

[6] N. S. Trahair, M. A. Bradford, D. A. Nethercot and L. Gardner, "The Behaviour and Design of Steel Structures to EC3".

[7] Anil K, Chopra, Dynamics of Structures, 2007 Edition.

[8] Mario Paz and William Leigh, Structural Dynamics, Theory and computation, $5^{\text {th }}$ edition.

[9] C. F. Beards, Structural vibration: Analysis and Damping.

[10] A Minigraph by Ajai S. Pisharady, A. D. Roshan and Vijay V. Methekar, Seismic Safety of Nuclear Power Plants

[11] Ziguo Xu, Chongcui Ren and Congzhen Xiao, CTBUH Research paper: The Aseismic design and nonlinear dynamic analysis of a $350 \mathrm{~m}$ high braced steel frame.

[12] Bungale S. Taranath, Wind and Earthquake resistant buildings structural analysis and design.

[13] E. Cruz, R. Garcia, G. Vera and D. Valdivia, "Evaluation of a Simplified Analysis Model for the Earthquake Response of a Coal Fired Boiler and its Steel Support Structure”, Journal of WCEE, The 14th World Conference on Earthquake Engineering, Beijing, China, October 12-17, 2008.

[14] T. Hari Krishna, M. Penchal Reddy and K. Baskar, "Static and Dynamic Analysis of Boiler Supporting Structure Designed Using Concrete Filled Square Steel Tubular Columns and Comparison with Structural Steel Columns”, International Journal of Science and Research (IJSR), Paper ID: 02015607, Vol. 3, No. 8, August 2014.

[15] Motoki Kato, Kunihiro Morishita, Masaki Shimono, Yasuharu Chuman, Takashi Okafuji and Toshiaki Monaka, "Development of Rational Design Technique for Frame Steel Structure Combining Seismic Resistance and Economic Performance”, Mitsubishi Heavy Industries Technical Review, Vol. 52, No. 1, March 2015.

[16] Kiyoshi Muto, Koji Shibata, Taunehisa Tsugawa and Kazuhiko Yamada, "Earthquake Resistant design of Boiler building of thermal power plant", Journal of WCEE, Proceedings of Ninth World Conference on Earthquake Engineering, Tokyo-Kyoto, Japan, Vol. 6, August 2-9, 1988.

[17] [Online] Available: https://strongmotioncenter.org/ 